\title{
Novedades en uropatología de interés clínico
}

\author{
González-Peramato P. \\ Servicio de Anatomía Patológica. Hospital Universitario de Guadalajara. Universidad de Alcalá. \\ Alcalá de Henares. Madrid. \\ Actas Urol Esp. 2007;31(9):941-942
}

$\mathrm{E}$ n la última década se han producido cambios sustanciales, tanto conceptuales como de diagnóstico, de los tumores del aparato urogenital, con definición de nuevas entidades. Estos cambios son, en parte, debidos al gran desarrollo de nuevos métodos tecnológicos (inmunohistoquímicos, moleculares....) aplicados al diagnóstico rutinario de los pacientes, lo que ha determinado un nuevo lenguaje de intercambio de conocimientos entre urólogos y patólogos. Surge así un nuevo paradigma de valoración de los pacientes que, respetando las entidades clínicopatológicas clásicas, cada vez está más enfocado a un diagnóstico personalizado de cada caso.

La Anatomía Patológica del Aparato Génitourinario está bien sistematizada en excelentes textos; sin embargo, la aplicación de nuevas tecnologías plantea la necesidad de realizar actualizaciones de temas concretos. En el presente número Monográfico de Uropatología que amablemente la revista Actas Urológicas Españolas y la Asociación Española de Urología me han propuesto coordinar como editora se abordan aspectos novedosos en Anatomía Patológica urológica. Siempre es difícil realizar una selección de temas uropatológicos que pueden ser de interés para el urólogo, pues evidentemente existen otros muchos temas interesantes que, por la extensión de este número monográfico, no se han podido revisar. Con todo, se ha tratado de incluir aquellos temas de mayor controversia, actualidad o puntos de encuentro entre Urólogos y Patólogos.

Este número monográfico comienza con un artículo que aborda la importancia de un adecuado intercambio de información que, desde el punto de vista del urólogo, es necesario que aporte el patólogo; a continuación se incluye una completa revisión de las indicaciones precisas de la biopsia intraoperatoria en la patología urológi- ca oncológica. Los dos siguientes artículos se centran en dos temas relevantes de patología renal: las neoplasias renales asociadas a alteraciones cromosómicas que se presentan en la infancia y adultos jóvenes en el que se evalúan entidades recientemente descritas y la importante contribución de la citología al diagnóstico de las masas renales y perirrenales, sobretodo en una época en que cada vez con mayor frecuencia se plantea la cirugía conservadora y mínimamente invasiva de las neoplasias renales. A continuación se revisan tres aspectos de la patología vesical, analizando y comentando la clasificación de las neoplasias vesicales, evaluando la importancia, ventajas y dificultades de la subestadificación de los tumores vesicales en el estadio T1; también se incluye una revisión de aquellas variantes de carcinoma urotelial que por su implicación diagnóstica o pronóstica merecen ser bien conocidas tanto por urólogos como por patólogos. Los tres artículos dedicados a la patología prostática abordan la revisión de los nuevos marcadores inmunohistoquímicos que son de en el diagnóstico diferencial entre el carcinoma de próstata y las lesiones simuladoras de cáncer, problemas que con cierta frecuencia se plantean en las cada vez más numerosas biopsias prostáticas; asimismo se incluye una revisión de los factores pronósticos y predictivos del carcinoma de próstata en estas biopsias y, por último, un estudio comparativo de la eficacia quirúrgica de la prostatectomía abierta y laparoscópica. En el apartado de la patología testicular se realiza una amplia revisión de la contribución de la anatomía patológica al diagnóstico de una patología tan variada como los estados intersexuales. En la sección de patología del pene se revisa la aplicación e indicaciones de la cirugía micrográfica de Mohs en las neoplasias del pene. Por último, se 
incluye un artículo acerca de la aplicación de nuevas tecnologias de microarray de anticuerpos, métodos que sin duda en los próximos años contribuirán a la ampliación del conocimiento de las neoplasias urogenitales.

Esperamos que los artículos incluidos sean de interés para los Urólogos y también para los Patólogos y deseamos que el presente número monográfico resulte de agradable lectura, dado que todos los autores han hecho un esfuerzo muy loable de revisión y sintesis de temas en los que son reconocidos expertos. Por ello, quiero expresar mi sincero agradecimiento a todos y cada uno de los autores por su colaboración y la excelente calidad científica de sus contribuciones. Quiero también agradecer al Dr. José Luis Ruiz Cerdá por ofrecerme la oportunidad de participar como editor invitado en este número Monográfico de Uropatología de la revista Actas Urológicas Españolas, revista a la que aprecio con especial cariño. Por último, si he aceptado la coordinación del presente Monográfico de Uropatología ha sido por el inestimable apoyo que permanentemente recibo de mis maestros los Dres. Manuel Nistal, María Luz Picazo y José $\mathrm{M}^{\mathrm{a}}$ Viguer a los que siempre les estaré agradecida; asímismo, mi sincera gratitud al Dr. Javier Regadera, por sus constantes y generosos consejos científicos y editoriales. Para mi, la coordinación del presente Monográfico de Uropatología de la revista Actas Urológicas Española ha sido una experiencia muy gratificante; por ello, deseo que puedan disfrutar de su lectura.

Correspondencia autora: Dra. P. González-Peramato Servicio de Anatomía Patológica Hospital Universitario de Guadalajara Avda. Donantes de Sangre, s/n. 19002 Guadalajara Tel.: 949209200

E-mail autora: mpgonzalez.hulp@salud.madrid.org Información artículo: Editorial 